\title{
Contribución al estudio de los grabados rupestres postpaleolíticos de la Península Ibérica: las manifestaciones del Alto Duero *
}

\author{
Juan A. Gomez-Barrera
}

En el marco físico del Alto Duero, Altimeseta Soriana o actual provincia de Soria cuya originalidad geográfica le es dada por su situación peninsular (zona de transición de la Meseta al Valle del Ebro), por ser cruce, fricción y soldadura de la Meseta, Sistema Ibérico y Sistema Central (determinantes de su altitud) y por la acción de su múltiple divisoria hidrográfica (Duero-Tajo-Ebro) ${ }^{1}$, son conocidas, desde principios de siglo, una serie de manifestaciones artisticas, de carácter rupestre, que fueron grabadas en el roquedo de las abruptas estribaciones de Sierra Pela y en las paredes de alguna de las cuevas del Valle de Ucero.

* El presente trabajo constituye el resumen de nuestra Tesis Doctoral, que bajo el título "Los grabados rupestres postpaleoliticos del Alto Duero" fue dirigida por el Dr. Don Eduardo Ripoll Perelló, Catedrático de Prehistoria y Profesor Emérito de la UNED. Fue defendida el 15 de abril de 1991, en la Facultad de Filosofia y Letras de la UNED ante el tribunal constituido por los doctores: Ana M. ${ }^{a}$ Muñoz Amilıbia, Mauro S. Hernández Pérez, Rosario Lucas Pellicer, Cruz Martínez de Latorre y Sergio Ripoll López, obteniendo la calificación de apto cum laude.

Miralbes Bedera, M. R., Contribución al estudio geoeconómico de Soria. Mercados geográficos y ferias. Zaragoza 1957, pág. 25; Pala BastaRas, J. M.; Calavia Redondo, M. molini Fernandez, F., y Silvan Sada, L., Análisis del Medio Físico de Soria. Delimitación de unidades y estructura territorial, Valladolid, Junta de Castilla y León, 1988, pág. 39; BACHILLER, J. M. ${ }^{a}$, y SANCHO, M. ${ }^{a} \mathrm{C}$., "Introducción al estudio del espacio geográfico soriano", Arevacón, 16 (1990). 


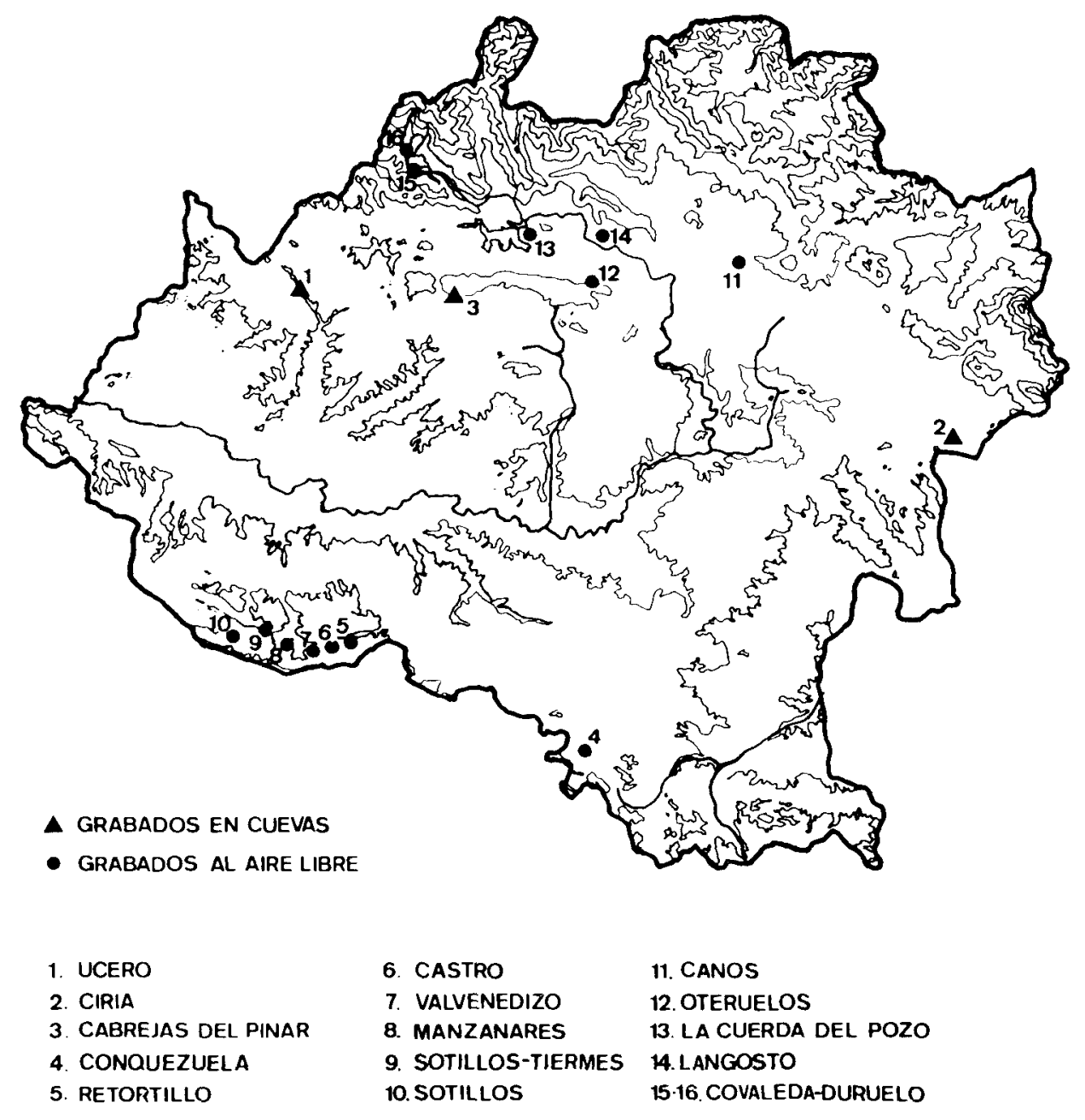

Fig. 1. Carta de distribución de los grabados rupestres postpaleolíticos sorianos. 
A los iniciales descubrimientos de J. Cabré ${ }^{2}$, Marqués de Cerralbo ${ }^{3}$, $\mathrm{S}$. González y $\mathrm{H}$. Breuil ${ }^{4}$ se irían añadiendo, con el transcurrir del tiempo y el avance de la investigación prehistórica, los de Conquezuela ${ }^{5}$, Ciria ${ }^{6}$, Oteruelos ${ }^{7}$ y Cabrejas del Pinar ${ }^{8}$ junto a otros vestigios de menor entidad grabados en los términos de Torrevicente, Lumías, Santamera, Cihuela, Deza, Canos, Duruelo de la Sierra, Covaleda, Calderuela, El Royo, Derroñadas, Langosto y Pantano de la Cuerda del Pozo ${ }^{9}$. La condición de hallazgos sueltos, aislados y sin peso específico propio de estos últimos, ha posibilitado centrar el estudio del grabado rupestre postpaleolítico soriano en las muestras de las cuevas de San Bartolomé, Covarrubias y Cueva Maja y en los covachos y abrigos al aire libre de Cueva de La Santa Cruz, Barranco de la Mata, Tiermes-Sotillos, Valle del Río Manzanares, Valvenedizo y Castro, Cañada del Monte, Barranco del Cuento del Cerro y Cueva Grande, lo que hace un total de once núcleos de arte rupestre que vienen asi a unirse, en el panorama artistico prehistórico de la Altimeseta Soriana, a un denso conjunto de abrigos con pintura esque-

2 Cabre Agullo, J., Catálogo arqueológico, histórico, artístico y monumental de la provincia de Soria, t. II: Neolítico y Edad del Cobre, 1912-1916, inédito; y “Pinturas y grabados rupestres, esquemáticos, de las provincias de Segovia y Soria", Archivo Español de Arqueologia, XLIII (1941), págs. 316-344.

${ }^{3}$ Cabré atribuye, en su El arte rupestre en España (Memorias de la Comisión de Investigaciones Prehistóricas y Paleontológicas, 1. Madrid 1915, págs. 88-89), parte de los descubrimientos de los grabados sorianos al trabajo del Marqués de Cerralbo y sus prospectores.

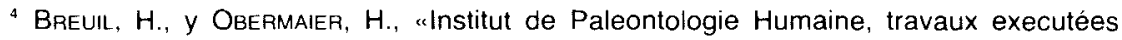
en 1912", L'Anthropologie, XXIV (1913), pág. 6.

5 Taracena Aguirre, B., Carta arqueológica de España. Soria. Madrid 1941, pág. 49; Ortego frias, T., "Los grabados prehistóricos de la Cueva de Santa Cruz, en el término de Conquezuela (Soria)", en Libro Homenaje al Conde de la Vega del Sella. Oviedo 1956. págs. 219-229.

"Ortego frias, T., "Covarrubias: una estación arqueológica en el término de Ciria (Soria)", X Congreso Nacional de Arqueologia (Mahón 1967). Zaragoza 1969, págs. 205215.

Ortego Frias, T., "Nueva estación de arte rupestre en el término de Oteruelos (Soria)", Celiberia, 48 (1974), págs. 217-228.

* Los grabados de Cueva Maja fueron descubiertos en 1986 por un grupo de profesores de la Cooperativa-Escuela "Del Rio" de Abioncillo a quienes agradecemos su gentileza en la comunicación del hallazgo y su ayuda en las tareas de documentación de los mismos.

${ }^{9}$ Las alusiones a la existencia de grabados en Torrevicente, Lumías, Santamera, Cihuela, Deza... aparecen en CABRE, J., Catálogo monumental... citado, pág. 88 y en El arte rupestre... citado, pág. 119 mientras que TARACENA recoge en su Carta arqueológica los grabados de Canos (pág. 49) y ORTEgo hace lo propio con las cazoletas de Calderuela, El Royo y Derroñadas en su artículo «Nueva estación de arte rupestre...", citado, págs. 223224. 


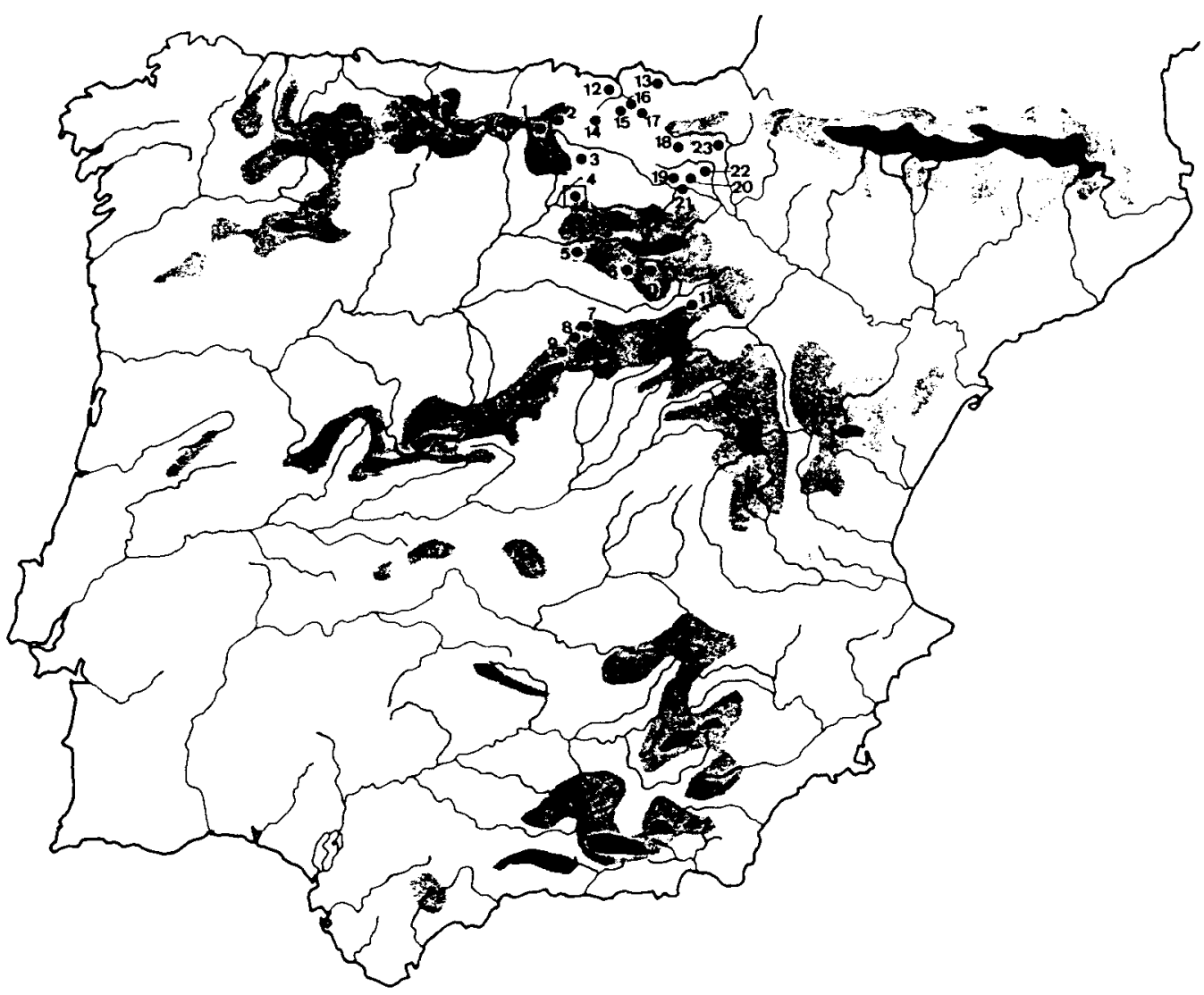

Fig. 2. Distribución de los grabados postpaleoliticos en cuevas del Centro-Norte de la Peninsula lbérica.

1. Complejo de Ojo Guareña; 2, Cueva del Portal (Lastra de las Heras, Burgos); 3, Cueva de Penches (Barcina de Los Montes, Burgos); 4, Complejo de Atapuerca; 5, Cueva de San García (Santo Domingo de Silos, Burgos); 6, Cueva Menor y Mayor de San Bartolomé (Ucero, Soria); 7, Los Enebralejos (Prádena, Segovia); 8, Cueva de la Griega (Pedraza, Segovia); 9, Cueva de La Fuente Dura (Losana del Pirón, Segovia); 10, Cueva Maja (Cabrejas del Pinar, Soria); 11, Covarrubias (Ciria, Soria); 12, Arenaza (Galdames, Vizcaya); 13, Goikolau (Berriatúa, Vizcaya); 14, Pico Corral (Bóveda, Álava); 15, Solacueva (Jócano, Alava); 16, Liciti (Andagoya, Álava); 17, Lazalday (Zárate, Álava); 18, Los Moros (Atauri, Álava); 19, Basaura (Berindano, Navarra); 20. San Martín (Laguardia, Álava); 21, Txabola de la Hechicera (Elvillar, Álava); 22, Peña del Cuarto (Learza, Navarra); 23, Peña del Cantero (Echauri, Navarra) 
mática localizados en el Monte Valonsadero, Pedrajas, Oteruelos, Fuentetoba, Ucero y Ligos $^{10}$.

Incluidos estilísticamente en el llamado "arte esquemático», tan amplio muestrario presenta, en principio, una diferenciación geográfica en su distribución: mientras que la pintura aparece en extensos parajes de pastos situados en la confluencia de caminos, valles y ríos descendentes de la Serranía Norte, los grabados en cuevas lo hacen en las zonas kársticas centrales del valle del Duero y los grabados al aire libre en los farallones y acantilados que proporcionan las alineaciones Este-Oeste del piedemonte del Sistema Central, en el suroeste de la provincia.

Tanto esta distribución diferencial -en el espacio y en el uso del soporte- como la diversidad técnica, temática y cronológico-cultural de los distintos grabados aconseja una clara división entre aquellas muestras plásticas trazadas en paredes y techos de galerias y cámaras de cavernas subterráneas y las que ocupan superficies irregulares, horizontales y verticales, de covachos y abrigos al aire libre. Su descripción y análisis (trazadas a partir de un intenso trabajo in situ y un completo material gráfico basado en 179 copias directas, a escala e inéditas, que suponen el calco aproximado de $180 \mathrm{~ms}$ de superficie grabada a lo largo de varios kilómetros de desarrollo) ha permitido catalogar 175 grupos grabados y 2.769 figuras, en un total de 73 estaciones artísticas. Cueva Mayor, Cueva Menor, Covarrubias y Cueva Maja presentan, en conjunto, 33 grupos o paneles grabados y 60 figuras frente a los 142 grupos y 2.709 motivos de las estaciones al aire libre sin que se pueda ver en ello otra connotación conclusiva que la derivada de la anotada diferenciación existente entre unas manifestaciones y otras. Las tablas tipológicas, cuadros estadísticos y gráficas de barras elaborados con su información han expuesto las características individualizadas de cada núcleo, facilitando la composición de otras tablas, cuadros y gráficas generalizados al conjunto

${ }^{10}$ Además de la amplia bibliografía de Ortego (reunida toda ella en Gomez-BARRERA, J. A., «D. Teógenes Ortego Frías y su aportación al estudio del arte rupestre postpaleolítico en la Península Ibérica", Celtiberia, 75, 1988, pág. 47-77), la pintura rupestre esquemática soriana ha generado otros muchos trabajos en los que ha sido intensamente analizada: Gomez Barrera, J. A., La pintura rupestre esquemática en la Altimeseta Soriana, Excmo. Ayuntamiento de Soria, 1982; Idem: "El Abrigo de "La Peña los Plantios": nuevo hallazgo de pinturas rupestres esquemáticas en Fuentetoba (Soria)", Ars Praehistórica, III-IV (198485), págs. 139-180 y Gomez-BARRera, J. A., y Borobio Soto, M. J., "Las pinturas rupestres esquemáticas de Cueva Conejos (Ucero, Soria)", I Symposium de Arqueologia Soriana. 1984, págs. 141-150. 


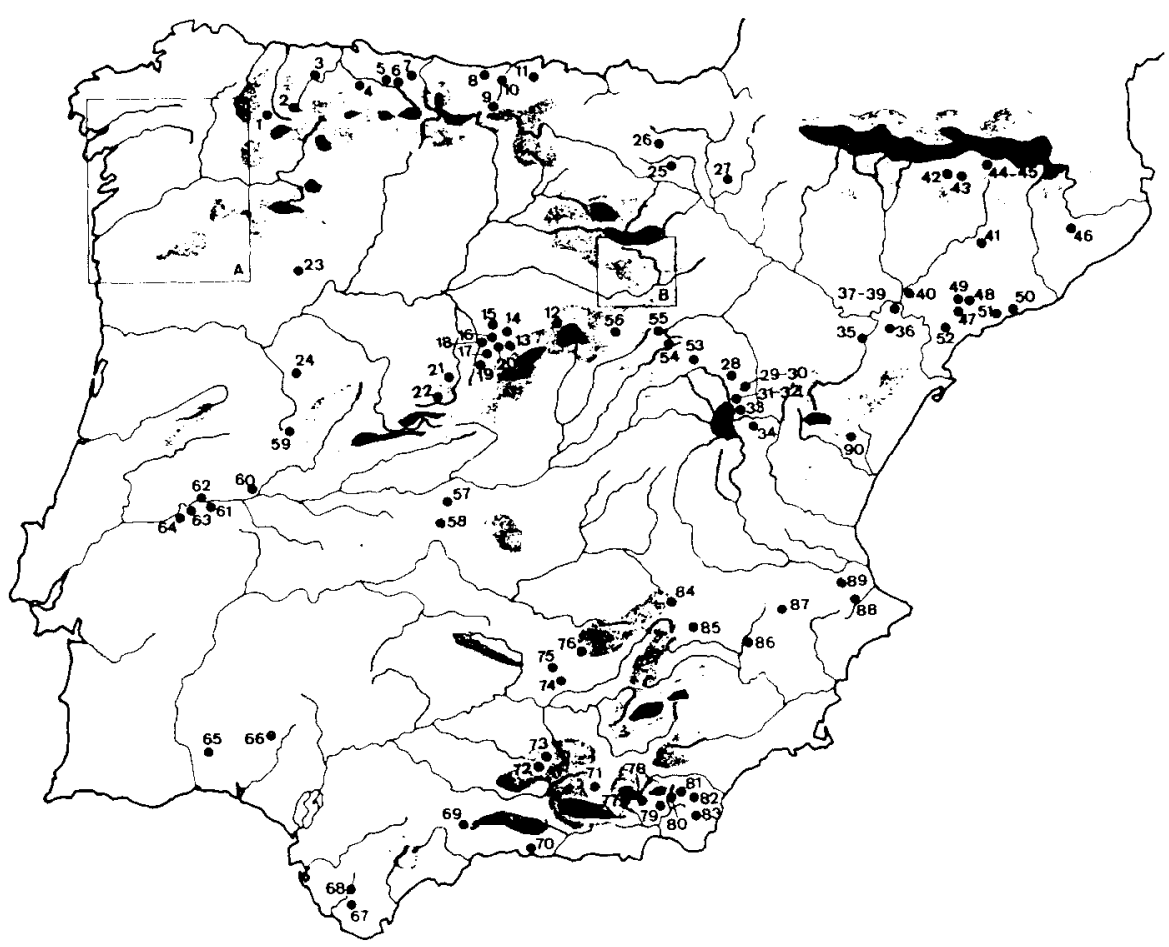

Fig. 3. Grabados rupestres postpaleoliticos al aire libre en la Peninsula lbérica. A) Ciclo galaico-portugués y B) zona de los grabados sorianos.

1. La Xorenga: 2, Pea Colmea y Monte de Tumba; 3, Los Chanones; 4, Picu Berrubia, 5. Picaxu; 6. Peña Corián; 7, El Llendón; 8. Peña Tú; 9. Sejos; 10, Braña de los Pastores; 11. Covacho de la Peñona; 12, Covacho del Molino Giriego; 13, Yanguas de Eresma, 14. Carbonero el Mayor; 15. Bemardos; 16. Santa María de Nieva; 17, Miguelañez; 18, Domingo Garcia; 19. Ochando; 20. Armuña; 21, Sierra Guadarrama; 22, Muñogalindo; 23, El Pedroso; 24, Yecla de Yeltes; 25. Peña del Cuarto; 26, La Borunda; 27, Beire; 28, Ródenas; 29. Peña de La Albarda; 30, Abrigo de los Tioticos; 31. Peña Escrita; 32, Puntal del Tío Garrillas; 33. Monterde de Alabarracín; 34, La Masada de Ligros; 35, La Coscollosa; 36. Las Peñetas; 37, Barranco de Valmayor; 38, Barranco de la Plana; 39, Barranco de Campells; 40, La Granja d'Escarp; 41. Mas de N'Olives; 42, San Miguel; 43, Arati; 44, Les Bruixes de Prats; 45, El Solá del Puy de la Massana; 46. Savassona; 47, Rocas de Las Ferradures; 48, Coll de la Mola; 49. Pla de la Guardia; 50. Coll de Creus; 51, El Pujol Rodó; 52, Roca de Rogerals; 53, La Peña Escrita de Canales; 54, Cueva del Robusto; 55. La Lastra; 56. Hijes; 57, Martinete; 58, La Nava de Ricomalillo; 59, Las Hurdes; 60, Esparrogosillo y Campos de Agua (Alcántara); 61-64, Sao Simao, Alagadouro, Lomba da Barca, Cachao de Algarve. Ficalho, Fratel, Cascalhiera do Tejo. Foz de Nisa, Chao de Velha, Silveira de Gardete; 65, Las Tierras; 66, Los Aulagares; 67, Laja de los Hierros; 68, Cueva del Arco y Tajo de Abarianes; 69, Arquillo de los Porqueros; 70, Nerja; 71, Cerro de la Mina; 72, Barranco de Estoril; 73, Barranco de la Tinaja; 74, Las Piedras Huecas; 75, La Española; 76, Poyo de en Medio de la Cimbarra; 77, Nacimiento; 78, Olula de Castro; 79, Tahal; 80, Chercos; 81, Ljar; 82, Piedra de la Cera; 83, Sorbas; 84, La Tinaja; 85, Grusareo; 86, El Canalizo El Rayo; 87, Monte Arabi; 88, Vall de Gallinera; 89, Barranc de L'Aguila; 90 , La Serradeta. 
de los núcleos grabados en cuevas y al aire libre sorianos y su comparación con otras zonas artísticas del territorio peninsular.

Las cuevas utilizadas como soportes de parte de los grabados rupestres postpaleolíticos del Alto Duero son de trazado horizontal y escaso desarrollo longitudinal, localizadas en las proximidades de cursos fluviales y en lugares destacados y de amplia visibilidad desde sus entradas. Se sitúan todas ellas en unidades ambientales de montaña menor y parameras, circunscribiéndose a un espacio biogeográfico de coníferas frondosas, matorral, pastizales y prados naturales que definen un marco paisajístico ambiental de aprovechamiento esencialmente ganadero con actividades complementarias de caza, pesca y recolección de vegetales y agricultura en la vega de los ríos.

Artísticamente, las cuevas sorianas presentan sus motivos distribuidos en superficies, más o menos rugosas, bien señaladas en el recinto y visibles dentro del marco espacial que las cobija. Su temática, más cerca de la abstracción y estilización lineal y geométrica que del esquematismo cognoscible, admite un cuadro tipológico en el que es fácil distinguir figuraciones -o motivos relacionables con un modelo real, que en el caso soriano se reducen a diversas formas antropomórficas-y representaciones lineales y geométricas conformando retículas, zig-zags, anguliformes, esteliformes, arboriformes, pectiniformes, motivos lineales horizontales o verticales y marañas. En este sentido es de hacer constar la ausencia, en todas las cuevas sorianas, de la representación animal constituyendo este hecho, junto con la escasa repercusión de los temas figurados y la reducción de los motivos antropomórficos a zonas concretas y menos accesibles a las cavernas (Cueva Maja), una caracterización del conjunto que avalaría la interpretación simbólica y sentido cultural de estas manifestaciones. Del mismo modo, resulta de máximo interés el papel desempeñado por los motivos reticulados en Cueva Maja, cuya distribución por el recinto artístico de la cueva parece responder a una intencionalidad ritual de delimitación del espacio sagrado del yacimiento ${ }^{11}$.

Técnicamente, en las cuevas sorianas se utilizan los soportes irregulares -que ofrecen hornacinas, oquedades, coladas, vetas cóncavas o convexas diseñadas en paredes verticales o estructuras techadaspara recibir el grabado, generalmente inciso en $V$ de trazo simple único y algún ejemplo abrasivo en $U$ y utilización marginal del repiqueteado.

"Gómez- Barrera, J. A., "Grabados rupestres postpaleoliticos en la provincia de Soria", en Arte Prehistórico de la Provincia de Soria, Museo Numantino, 1990, págs. 102-104. 


\begin{tabular}{|c|c|c|c|c|c|c|c|c|c|c|c|c|c|c|c|c|c|c|c|c|}
\hline \multicolumn{3}{|c|}{$\begin{array}{l}\text { GRABADOS RUPESTRES } \\
\text { DEL ALTO DUERO }\end{array}$} & \multirow{2}{*}{\begin{tabular}{|l|} 
CuE \\
WA \\
DE \\
S \\
CRuZ \\
\\
\end{tabular}} & \multicolumn{11}{|c|}{ BARRANCO DE LA MATA } & \multicolumn{5}{|c|}{$\begin{array}{l}\text { TIERMES- } \\
\text { SOTILLOS }\end{array}$} & \\
\hline \multirow{4}{*}{$\begin{array}{l}\text { SITUACION DE } \\
\text { LOS AIBHCOS }\end{array}$} & \multirow{3}{*}{\multicolumn{2}{|c|}{ 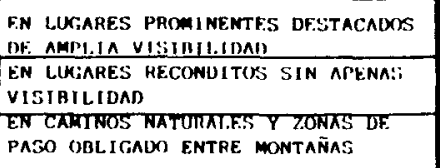 }} & & - & $\bullet \bullet$ & & & & & & & & & & & & $-1 \cdot$ & 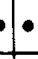 & & \\
\hline & & & & & & & & & & & & & & & & & & & & \\
\hline & & & & & & & & & & & & & & & & & & & & \\
\hline & \multirow{3}{*}{\multicolumn{2}{|c|}{$\begin{array}{l}\text { CEICANOS A RIOS } \\
\text { CERCANOS A YAC. ARQUEOLOGICOS } \\
\text { SUPERFICIES ROCOSAS AL. AIRE LIBHE } \\
\text { OOUEDAOFS ROCOSAS DE PEQUET̃AS } \\
\text { DIMENSIONES }\end{array}$}} & $\because$ & $\bullet$ & 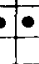 & $\bullet$ & $\cdot$ & $\bullet$ & -] & & te & to & & $\because$ & & & & & & \\
\hline \multirow{4}{*}{$\begin{array}{l}\text { CONFICURACION } \\
\text { OE LOS } \\
\text { ABRICOS }\end{array}$} & & & & & & & & & & & & & & & & & & & & \\
\hline & & & & & & & & & & & & & & & & & & & & \\
\hline & \multicolumn{2}{|c|}{ 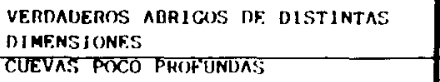 } & & & & & & & & & & & & & & & • & & & \\
\hline & \multicolumn{2}{|c|}{ AUTENTICAS CAVE.RMAS } & & & & & & & & & & & & & & & & & & \\
\hline \multirow{3}{*}{$\begin{array}{l}\text { SITUACION DE } \\
\text { LOS GRABADOS } \\
\text { DENTRO DE CADA } \\
\text { AHRIGO }\end{array}$} & \multirow{2}{*}{\multicolumn{2}{|c|}{ 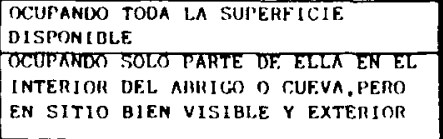 }} & & & $\bullet$ & & & & & & & & & - & & & & & & \\
\hline & & & $\bullet$ & & - & & & & & & & & & & & & & & & \\
\hline & \multicolumn{2}{|c|}{$\begin{array}{l}\text { EN LOS SITIOS MAS RECONUITOS E } \\
\text { INVEROSIMILES DE LOS ABRIGOS }\end{array}$} & & & & & & & & & & & & & & & & & & \\
\hline \multirow{13}{*}{$\begin{array}{l}\text { TEMAS } \\
\text { REPRESENTADOS } \\
\text { F.N LOS } \\
\text { ABHIGOS }\end{array}$} & \multirow{3}{*}{\multicolumn{2}{|c|}{$\begin{array}{l}\text { IDOLOS Y RITOS FUNERARIOS } \\
\text { FYGURAS HUMANAS } \\
\text { FTUURAS ANIMALES } \\
\end{array}$}} & 1 & & & & & & & & & & & & & & & & & \\
\hline & & & 48 & 1 & 9 & & & 1. & & & & & & 30 & 52 & & & 4 & 24 & \\
\hline & & & 1 & & $1 3 \longdiv { 3 1 }$ & & 5 & & 1 & & $\sqrt{2}$ & & & & 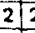 & & & & & \\
\hline & \multirow{10}{*}{$\begin{array}{l}\text { UTHOS } \\
\text { MOTIVOS } \\
\quad \text { Y } \\
\text { ORETOS } \\
\text { DETEHMINADOS }\end{array}$} & \begin{tabular}{|l} 
TECTIFOKMES \\
ARMAS
\end{tabular} & & & 10 & & & 1 & & & 11 & & & 3 & & & & & 2 & \\
\hline & & \begin{tabular}{|l|} 
ARARS \\
HERADURAS
\end{tabular} & & & & & & & & & 217 & & & & & & & & & \\
\hline & & ESPIRALIFORMES & & & $T_{2}$ & & & & & & & & 4 & & & & & & 2 & \\
\hline & & RAMIFORMES & & & & & & & & & & & & & & & & & & \\
\hline & & BARRAS & 5 & 2 & 11 & & & & & & & & & 5 & 2 & & & & 13 & \\
\hline & & PUNTOS & & & & & & & & & & & & 1 & & & & & & \\
\hline & & ESTILIFORAES & & & & & & & & & & & & 1 & & & & & & \\
\hline & & PECTINIFORMES & & & & & & & & & & & & & & & & & & \\
\hline & & СIACUI & & & 12 & & & 5 & & & & & & 3 & & & & & 2 & \\
\hline & & \begin{tabular}{|l|} 
SAREOLTETAS \\
CAZOLET \\
\end{tabular} & $\frac{6}{1226}$ & & & & & & & & & & & & & & & & & \\
\hline \multirow{8}{*}{$\begin{array}{l}\text { DISTRIBUCION } \\
\text { DE TEMAS } \\
\text { GRABADOS EN } \\
\text { CADA ABRICO }\end{array}$} & \multirow{2}{*}{\multicolumn{2}{|c|}{$\begin{array}{l}\text { ESTACIONES RUPESTRES QUE PRESENTAN } \\
\text { TODA CLASE DE MOTIVOS EN AMALGAMA }\end{array}$}} & - & & & & & & & & & & & & & & & & & \\
\hline & & & - & & - & & & & & & & ( & & - & & & & & $\bullet$ & \\
\hline & \multicolumn{2}{|c|}{$\begin{array}{l}\text { UNICA PRESENCIA O PFEDOM INIO OE } \\
\text { TEMAS SACADOS DE LA VIDA REAL, } \\
\end{array}$} & & & 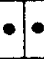 & & $\bullet$ & & & & & & & & & & & & $\cdot$ & \\
\hline & \multirow{2}{*}{\multicolumn{2}{|c|}{\begin{tabular}{|l|} 
UNICA EXIST.PPEDOMINIO DE IDOLOS \\
PREDOMINIO DE MITIVOS EN CAZOLETAS \\
\end{tabular}}} & & & & & & & & & & & & & & & & & & \\
\hline & & & $\bullet$ & & & & & & & & & & & & & & & & & \\
\hline & UNICA PRESENCI & DE FIG. ANIMAL & & & & $\bullet$ & & & & & & & & & & -1 & & & & \\
\hline & PRF.DOMINIO DE & OTIWOS EN HERAADURA & & & & & & - & - & & - & & & $\bullet$ & & & & & & \\
\hline & ABRICOS CON 1 , & Ó MENUS DE 5 FIGS. & & 0 & & $\bullet$ & & & & - 1 & & & & & $\cdot 1$ & & & & & $\bullet$ \\
\hline
\end{tabular}

Aplicación del esquema interpretativo de Breuil-Acosta a los grabadt 


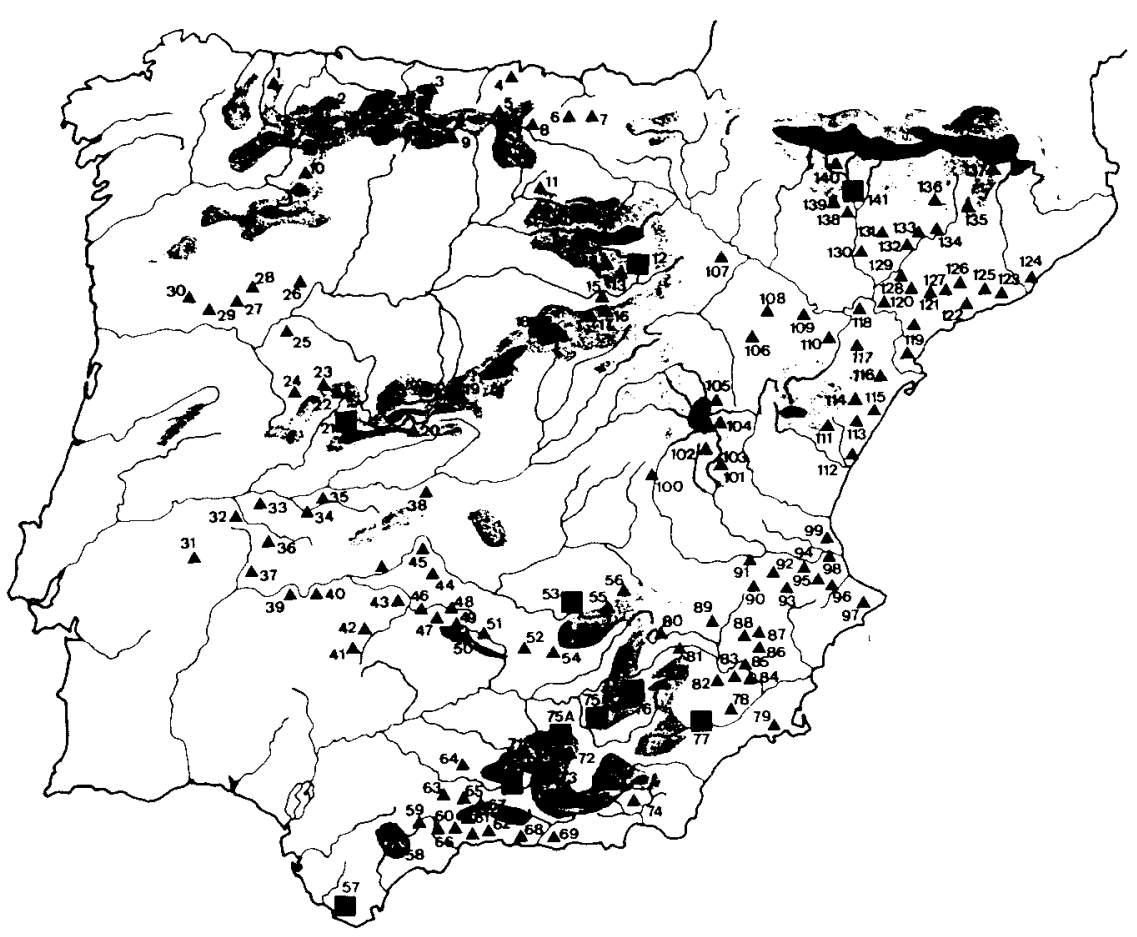

Fig. 4. Dispersión peninsular de la pintura rupestre esquemática

1. Cova del Demo; 2. Abrigos de Fresneu. Teverga; 3, Peña Tú; 4, El Castillo; 5, El Cogular, Ruanales; 6. Solacueva; 7, Lazalday: 8, Atapuerca; 9, Los Burros. Camasobres; 10, Sesamo. Vega de Espinareda; 11. Orbaneja del Castillo; 12, Monte Valonsadero. Pedrajas. Oteruelos (Soria); 13, La Peña los Plantios (Fuentetoba, Soria); 14, Cueva Conejos y La Galiana (Ucero, Soria); 15, Ligos: Abrigo del Este y del Oeste.; 16. El Portalón. Villacadima (Guadalajara); 17, Muriel (Guadalajara); 18, Barranco del Duratón (Segovia); 19, Ojos Albos (Ávila); 20. Raso de Candeleda (Ávila); 21. Valle de Las Batuecas (Salamanca), Valle de Las Esposadas, Valle de Lera, Valle de Belén y abrigos de Sierra del Cabril-Castillo; 22, Las Quilamas; 23, Peñas del Gato; 24, Bonete del Cura; 25, Palia Rubia; 26. El Castillón. Sta. Eulalia de Tabara; 27, Mogadouro (Penas Roias); 28, Sierra de la Culebra; 29, Carraceda de Ansiaes (Cachao de Rapa): 30. Alijo (Pala Pinta); 31, Arronches; 32, El Buraco: Santiago de Alcántara: 33, Los Ojeros (Sierra de Clavería, Cáceres); 34, Las Corchuelas (Cáceres); 35. Castillo de Montfragüe; 36, Abrigo de Alpotreque (Badajoz); 37, Riscos de San Blas, Riscos de la Mantequera; 38. El Martinete, Alcaudete de la Jara (Toledo); 39, Abrigos de la sierra de San Serván; 40, Cerro de la Oliva, Las Vinas, Atalaya de Alange. Solana del Castillo, Muro del Castillo; 41, Hornachos. La Silla; 42, El Zarzal; Moriscas del Helechal, Puerto de las Ruedas, $C$. de P. Amarillo de las Grajas; 43. Buitres de Peñalsordo, Cerro Estanislao, Barranco de la Higuera; 44, Castañar, Estrechura del Lobo; 45, El Ratón, Muro de Helechosa; 46, Abrigos de la Sierra de la Virgen del Castillo; 47, Sierra de la Hoyuelas. Castillo de Aznarón; 48, Sierra de Cordoneros; 49, Abrigos de Almodovar del Campo y Fuencaliente: 50-51, Abrigos de Solana del Pino, Mestanza y San Lorenzo de Calatrava; 52, Mamellado. Callejones de la Cepera; 53, Abrigos de Despeñaperros y Aldeaquemada; 
Por lo demás y en lo hasta ahora conocido es evidente la ausencia total de huellas de pintura que pudieran señalar la coexistencia de ésta con el grabado como, contrariamente, ocurre en otras cuevas de la Meseta Norte (Los Enebralejos, La Vaquera, Galeria del Silex, Kaite II y Keimada) ${ }^{12}$ y zona Cantábrica (Solacueva, Lazalday y Los Moros) ${ }^{13}$.

12 Municio Gonzalez, L., y Piñón VARela, F., "Programa de documentación y estudio de la Cueva de Los Enebralejos (Prádena, Segovia)", Bajo Aragón. Prehistoria, VII-VIII (1986-87), págs. 133-146 y "Cueva de Los Enebralejos (Prádena, Segovia)", Numantia III (1990), págs. 51-76; Municio Gonzalez, L., y Zamora Canellada, A., "Notas sobre grabados y pinturas asociados a necrópolis colectivas calcolíticas: los conjuntos de las cuevas de Los Enebralejos y de La Vaquera (Segovia)", Trabajos de Prehistoria, 46 (1989), págs. 271. 278; Apellaniz, J. M., y Uribaral, J. L., “Estudios sobre Atapuerca (Burgos). I. El Santuario de la Galeria del Silex". Cuadernos de Arqueologia de Deusto, 5, Bilbao 1976: UriBarri, J. L., y LIZ, C., "El arte rupestre de Ojo Guareña. La Cueva de Kaite", Trabajos de Prehistoria, 30 (1973), págs. 69-120; Ortega Martinez, A. I., y Martin Merino, M. A., "La arqueología del Karst de Ojo Guareña", Kaite. Estudios de Espeleología Burgalesa, Grupo Espeleológico Edelweiss. Excma. Diputación Provincial de Burgos, 4-5 (1986), págs. 331-389.

${ }^{13}$ LLANOS, A., "Algunas consideraciones sobre la cavidad de Solacueva y sus pinturas

\section{$\leftarrow$}

54, Los Organos; 55, Tabla del Porchico, Poyo del Medio. Felicitá, Los Arcos, Barranco de la Cueva; 56, Murcielaguilla de Cepera; 57, Cádiz. Conjunto del Tajo de las Figuras y abrigos pintados de la provincia; 58. La Pileta; 59, Abrigo Raja de Retuntun; 60, Sima de la Curra; 61, Casabermeja; 62. Cueva de la Victoria (La Cala. Málaga); 63, Porqueros; 64, La Murcielaguina; 65, Abrigos de la Sierra de Camarolos; 66, Complejo de Venta del Fraile; 67, Abrigo del Tajo del Vilo (Alfarnalejo); 68, Nerja; 69. Llanos de Carchuna; 70. Núcleo de Moclin: 71, Núcleo Sur de Jaén; 72-73, Núcleo de la Sierra de la Arana; 74, Núcleo de la Sierra de los Filabres; 75A. Núcleo de la Sierra Mágina; 75, Núcleo de la Sierra de Quesada; 76, Núcleo Noroeste de Granada; 77, Núcleo Norte de Almería; 78, Tío Labrador y Paradores (Lorca): 79, La Higuera (Isla Plana); 80, Collado del Guijarral; 81, Solana del Molinico; 82, La Risca (Moratalla). El Calar de la Santa (El Sabinar); 83, La Peña Rubia (Ceheguin); 84, Abrigo del Cejo Cortado y El Milano (Mula): 85, Los Grajos, La Serreta y Las Enredaderas (Cieza); El Pozo (Calasparra); 86, La Calesica (Jumilla); 87, El Peliciego (Jumilla): 88, Buen Aire (Jumilla); 89, Canalizo El Rayo. Minateda. Barranco de la Mortaja; 90. Cantos de la Visera. Mediodia del Arabi; 91, La Vieja. Cueva Negra; 92, Ayora (Valencia); 93, Barranc del Bosquet (Moixent, Valencia); 94, La Araña de Bicorp; 95, Estret de Les Aigües (Xativa); 96, Beniatjar. Vall d'Albaida (Barranc de Carbonera, Coveta del Mig y Salem); 97, Peña Escrita de Taberna; 98, Pernil; 99, Ciento de la Ventana; 100, Anear, El Escrito, Bullón; 101, Peña de Aldebarán; 102, Villar del Humo: Marmalo y Castellón de los Machos; 103, Peña del Castellar; 104, Frias de Albarracin; 105, Prado del Navazo. Doña Clotilde; 106, Obón: La Coquinera; 107, Borja; 108, Albalate del Arzobispo: Los Estrechos; 109. Alcañiz; 110. Beceite: La Fenellosa; 111, La Cova de Gargán, Xodos (Castellón); 112, Castillo de Villafamés; 113, Tolls Alts; 114, Ares del Maestre (Castellón); 115, Civil; 116, Abric $V$ de Ulidecona; 117, Cova Pintada; 118, Val del Charco del Agua Amarga; 119, Cova del Pi; Cova de Les Calobres; 120. Mequinenza; 121, Mas d'en Carles; Mas d'en Britus I y $\mid$ | y Cova de Les Creus; 122, Cova de Vallmajor; 123, Cova dels Segarulls; 124, Pedra de Les Orenetes; 125, Cova de Can Castellvi; 126, Portell de Les Lletres; 127, Mas d'en Llort; 128, Cova de Cogul; 129, Cova d'Alfés; 130, Forau del Cocho (Estadilla, Huesca); 131, Cova dels Vilasos; 132, Cova del Tabac; 133, Les Aparets; 134, Cova d'Antona; 135, Cova dels Moros; 136, Cova del Cogulló; 137, Cova de la Vall d'lingla; 138, Alquezar (Huesca); 139, Lecina; 140, Valle de Añisclo; 141, Rio Vero (Huesca) 
En las cuevas de San Bartolomé se graba en las paredes verticales, sólo en una pequeña parte de ellas, y a la izquierda de la entrada recibiendo iluminación natural dada su proximidad. En Covarrubias y Cueva Maja por contra, los grabados son interiores y mientras en la primera las manifestaciones ocupan tanto la pared como la techumbre situadas a la izquierda de la galería principal, llenando con sus incisiones toda la superficie disponible de la zona e ignorando el resto de la cavidad, en Cueva Maja se da un programa de distribución más complejo y ciertamente intencionado en orden a una funcionalidad cultural del yacimiento, tal y como denuncian la concentración de grabados en puntos periféricos de la galería principal y galería baja, en el frontal norte de la antesala y en zonas recónditas de los camarines.

Como ocurre en la pintura, se aprovechan también diferentes accidentes geomortológicos del soporte para configurar o completar el motivo representado y, por el momento, no queda claro el uso reiterado de un mismo soporte y más bien se ha de pensar que los paneles grabados lo fueron en una única etapa de ejecución o bien, en el caso de producirse varias, se aprovecharon soportes próximos no grabados con anterioridad.

Tanto el estudio tipológico individualizado como el realizado a nivel de ciclo artístico, han puesto de manifiesto los múltiples paralelos estilísticos existentes entre las cavernas sorianas y aquellas otras que se abren por la zona nororiental y oriental de los rebordes montañosos de la $\mathrm{Me}$ seta Norte y su prolongación por el extremo oriental de la región cantábrica. Garcia-Soto, Moure Romanillo, Municio González, Piñón Varela, Alonso Zamora y Bécares Pérez, en diferentes publicaciones ${ }^{14}$, habian señalado estas semejanzas dentro de un horizonte cultural que las agru-

rupestres (Jócano, Álava)", Munibe, 1 (1961), págs. 45-64; "Resumen tipológico del arte esquemático en el Pais Vasco-Navarro". Estudios de Arqueologia Alavesa. I (1966), págs. 149-158 y “Avance a un planteamiento sobre el arte rupestre esquemático-abstracto en el Norte de España", XIV Congreso Nacional de Arqueologia (Vitoria 1975). Zaragoza 1977, págs. 645-648. DE Balbin BeHRMANN, R., “El arte megalítico y esquemático del Cantábrico», en (M. R. González Morales, ed.) Cien Años Después de Sautuola, Santander 1989, págs. $15-96$

14 Garcia-Soto Mateos, E., y Moure Romanillo, A., "Los grabados esquemáticos de San Bartolomé de Ucero (Soria)", I Symposium de Arqueologia Soriana, 1984, pág. 157; Moure Romanillo, J. A. y Garcia-Soto Mateos, E., "Los grabados de la Cueva de San Garcia (Santo Domingo de silos, Burgos)", Numantia II (1986), pág. 202; MuniCIO GonzALEZ, L., y PINNON VARELA, F., "Programa de documentación...", citado, pág. 142 y "Cueva de Los Enebralejos...", citado, pág. 74; Municio Gonzalez, L., y Zamora Canellada, A., "Notas sobre grabados y pinturas...", citado, pág. 271; BECARES PEREZ, J., "Arte rupestre prehistórico en la Meseta", Arte Rupestre en España (Revista de Arqueologia), 1987, pág. 93. 
paría e, incluso, el último de ellos hablaría del ciclo artístico de Solacueva-Galería del Sílex.

En concreto se trata del diseño de una "provincia artística" que se desarrollaría en el centro-norte de la Península, englobando al menos 38 yacimientos en cuevas de las provincias de Segovia, Soria, Burgos, Navarra, Álava, Vizcaya y Cantabria. Del breve inventario trazado en el capítulo IV de nuestro trabajo se pueden inferir algunos datos significativos como la utilización del grabado - generalmente inciso-en 29 de los yacimientos analizados, coexistiendo en ocho casos en la pintura y siendo ésta usada como única técnica en seis cuevas de Álava y Cantabria. Su tipología temática admite, en igual proporción a los ejemplos sorianos, la doble división de figuraciones y motivos más abstractos, si bien entre aquellos aparece la figura animal (en Los Enebralejos, La Vaquera, San García, Galería del Silex, Kaite II, Chipichondo, Galería de la Fuente, Sala de los Grabados y Goikolau) ausente de las cavernas sorianas. Entre las abstracciones son corrientes los zig-zags, retículas, ángulos, heliomorfos o esteliformes y circuliformes, ramiformes, pectiniformes, rayados o haces de líneas y marañas, con particularidades individuales que pueden personalizar a cada una de las cuevas pero no disociarlas del ciclo.

Elemento importante y definitivo en el estudio y sistematización del ciclo artístico representado por las cuevas del centro-norte peninsular será la constatación, en buena parte de ellas, de yacimiento arqueológico que bien pudiera contextualizar las manifestaciones artísticas. Entre las sorianas, tal y como aqui se ha recogido, el yacimiento arqueológico falta en San Bartolomé - aunque el horizonte cultural de sus alrededores sitúan sus cuevas en la Edad del Bronce ${ }^{15}$ - y ha sido objeto de excavación en Covarrubias y Cueva Maja. Ortego excavó en Covarrubias ${ }^{16}$ y sus resultados denuncian dos momentos diferentes de ocupación: uno tardorromano y otro postcampaniforme con decoraciones incisas en zigzags, triángulos, bandas rellenas de trazos oblicuos y líneas cosidas en sus cerámicas decoradas, paralelizables con el yacimiento al aire libre de Los Tolmos de Caracena ${ }^{17}$ fechable en el Bronce Medio. Cueva Maja, por su parte y en espera de los análisis del $\mathrm{C}-14$, ofrece un único nivel de ocupación cuyo material arqueológico correspondería al Bronce Antiguo como atestiguan sus paralelos con los yacimientos de El Parpantique

\footnotetext{
15 Garcia-Soto Mateos, E., y Moure Romanillo, J. A., "Los grabados esquemáticos de San Bartolomé...", citado, pág. 159.

${ }^{16}$ Ortego Frias, T., "Covarrubias: una estación...", citado, pág. 213.

17 Jimeno Martinez, A., "Los Tolmos de Caracena (Soria)", Excavaciones Arqueológicas en España, 134 (1984), pàg. 54.
} 


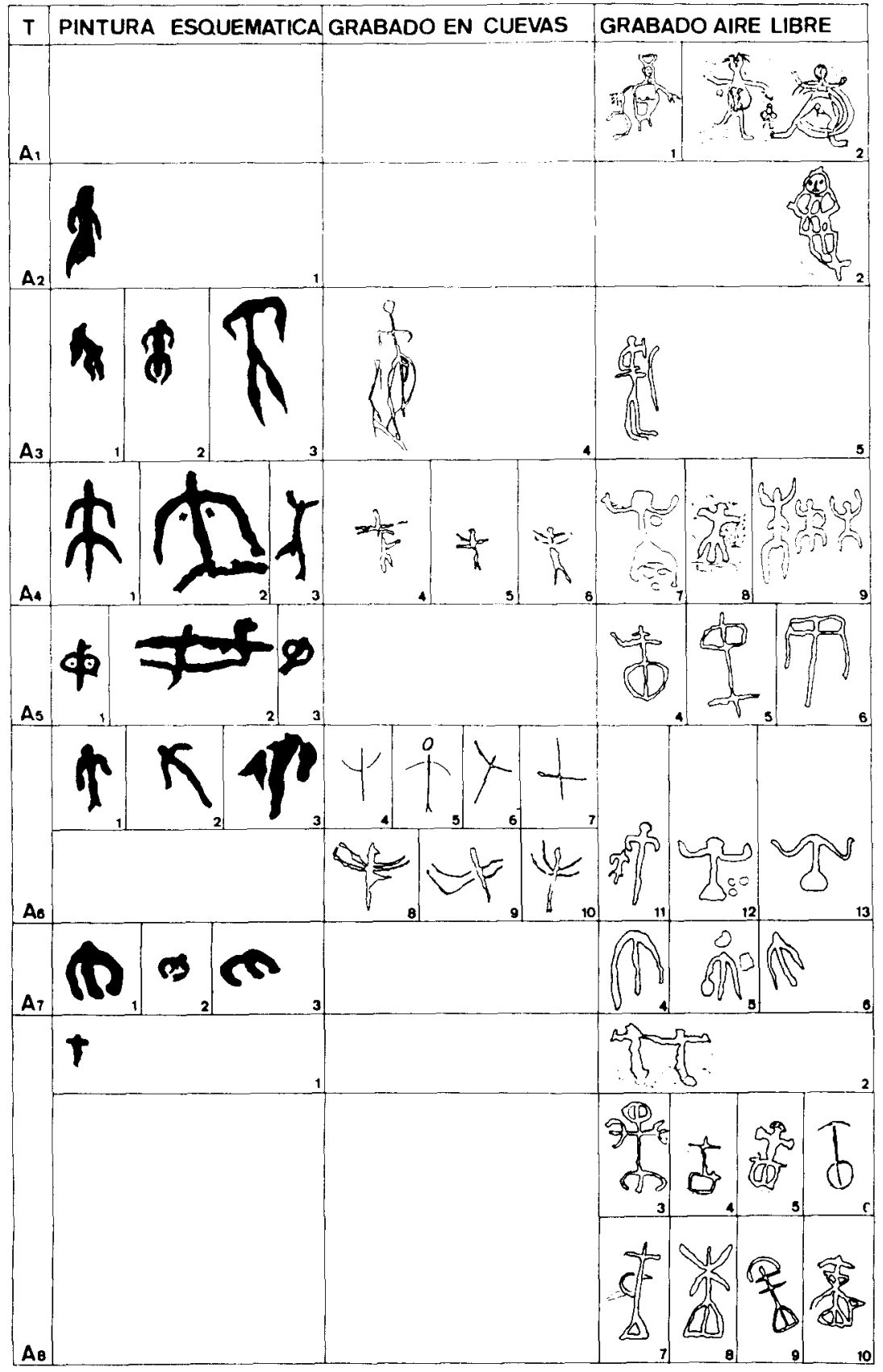

Fig. 5. Tipología comparada: antropomorfos. 
de Balluncar y Los Torojones de Morcuera, datados con C-14 en 17701780 a. C. y 1670 a. C., respectivamente ${ }^{18}$.

Aún a falta de excavaciones sistemáticas en gran parte de los yacimientos considerados (o de las publicaciones correspondientes a los ya analizados), la mayoría de las cuevas que compondrian la referida provincia artística del centro-norte de la Península presentan un horizonte cultural relacionable, arqueológica y cronológicamente, con los yacimientos sorianos. Las cuevas segovianas de Los Enebralejos (Prádena) y La Vaquera (Torreiglesias) han documentado sendas necrópolis calcolíticas de inhumación colectiva, evidencias de una intensa actividad cultural y la supuesta vinculación del arte rupestre de sus paredes y techumbres -grabados y pinturas - con la utilización de las cuevas como espacios sepulcrales ${ }^{19}$.

Las burgalesas de San García (Santo Domingo de Silos) ${ }^{20}$, Galería del Silex (Atapuerca, Ibeas de Juarros) ${ }^{21}$, Penches (Barcina de los Mon-

${ }^{18}$ En Cueva Maja se han llevado a cabo en estos últimos años dos campañas de excavaciones arqueológicas, bajo la dirección conjunta de A. Jimeno Martínez, J. J. Fernández Moreno y J. A. Gómez-Barrera y cuyos estudios se están realizando en la actualidad. Sobre los yacimientos del Bronce Antiguo soriano puede verse: JIMENo MARTinEZ, A., "La investigación del Bronce Antiguo en la Meseta Superior". Trabajos de Prehistoria, 45 (1988), pág. 114

19 Municio Gonzalez, L, y Zamora Canellada, A., "Notas sobre grabados y pinturas...", citado, pág. 274

20 Moure Romanillo, J. A., y Garcia-Soto Mateos, E., "Los grabados de la Cueva...", citado; Garcia-Soto Mateos, E., y Moure Romanillo, J. A., "El arte rupestre de la cueva de San García (Santo Domingo de Silos, Burgos) y otras manifestaciones parietales esquemáticas de la Submeseta Norte", XVIII Congreso Nacional de Arqueologia (Canarias 1985). Zaragoza 1987, págs. 513-523.

${ }^{21}$ Apellaniz, J. M., y URibarRi, J. L., "Estudios sobre Atapuerca...", citado; Apellaniz. J. M. y DOMingo MENA, S., "Estudios sobre Atapuerca (Burgos). II. Los materiales de superficie del Santuario de la Galería del Sílex", Cuadernos de Arqueologia de Deusto, 10. Bilbao 1987.

A.1: 1 y 2: Los Poyatillos.-A.2: 1: Abrigo I del Barranco de Valdecaballos; 2: Abrigo 16 de La Cañada del Monte.-A.3: 1: Peñón del Camino de Pedrajas; 2: Covacho del Morro; 3: El Pasadizo; 4: Covarrubias; 5: Motivo 1 del Abrigo 7.E. de Tiermes-Sotillos.-A.4: 1 y 2. Los Peñascales; 3: El Mirador; 4, 5 y 6: Cueva Maja; 7 y 9: Cueva de La Santa Cruz y 8. Abrigo núm. 8 de La Cañada del Monte-A.5: 1: Covachón del Puntal; 2: Camino a La Lastra; 3: Abrigo del Pozo; 4: Grupo G. de La Cerrada de La Solana; 5: Abrigo 1 del Barranco de la Mata; 6: Abrigo 6C del Barranco de La Mata.-A.6: 1: El Mirador; 2: Abrigo I del Barranco de Valdecaballos; 3: Abrigo del Pozo; 4 y 5: Cueva Mayor; 6, 7, 8, 9 y 10 Cueva Maja; 11: Cañada del Monte: Abrigo 20; 12 y 13: Cueva de La Santa Cruz.-A.7: 1 y 2: Abrigo del Pozo; 3: La Tronera; 4: Grupo E de La Cerrada de la Solana; 5 y 6: Cueva de la Santa Cruz.-A.8: 1: Cueva Grande; 2, 4 y 5: Abrigo 2 del Valle del Rio Manzanares; 3: Abrigo 7 de La Cañada del Monte; 6. Abrigo 9 de Valvenedizo-Castro; 7: Abrigo 8 del Valle del Río Manzanares; 8: Grupo J de La Cerrada de La Solana; 9: Grupo A de La Cerrada de La Solana y 10: Abrigo 4 del Valle del Río Manzanares. 
tes) ${ }^{22}$ y las cavernas y galerías del complejo kárstico de Ojo Guareña (Cueva de Sotoscueva) ${ }^{23}$, pese al ya necesario e imprescindible estudio exhaustivo de estas últimas, muestran un importante conjunto artístico encajable en el ciclo analizado y con yacimientos arqueológicos constatados en San Garcia y Galería del Silex y denunciado, a través de hallazgos de superficie, en Kaite II, Chipichondo, Keimada y Kubia. Moure y Garcia-Soto piensan que estos yacimientos decorados podrian atribuirse, en base a sus restos arqueológicos, a poblaciones de la fase Protocogotas y Cogotas I, no descartando un origen o precedente de sus grabados y pinturas en el Bronce Antiguo meseteño ${ }^{24}$. Esta atribución cultural para el ciclo artístico descrito quedaría confirmada de alguna forma, y pese a la escasez de datos arqueológicos referidos a los yacimientos situados en la zona oriental cantábrica, por la fecha radiocarbónica de $1760 \pm 100$ a. C., obtenida por A. Llanos en Solacueva (Jócano) ${ }^{25}$ y la asociación de las primeras manifestaciones artísticas esquemáticas alavesas a un ambiente de cerámicas lisas o decoradas con cordones plásticos.

Tales atribuciones culturales bien podrían cuestionarse si no fuera por las, aunque escasas, cada vez más claras asociaciones directas entre las manifestaciones artísticas y las arqueológicas que, en el ciclo que nos ocupa, estarian definidas por los paneles de los Grupos $\mathrm{H}$ y J de Cueva Maja y el fragmento de fondo cerámico con reticulado inciso en su pared exterior, los antropomorfos del panel XXV de la Galería del Silex y la figuración del vaso $\mathrm{C}-12$ obtenido al pie de las muestras rupestres y el ídolo calizo con representación pectiniforme similar a otras de igual carácter grabadas en la cueva de Los Enebralejos ${ }^{26}$.

22 Ripoll Perello, E., "Revisión de la cueva de Penches", IV Congreso Nacional de Arqueología (Burgos 1955), Zaragoza 1957, págs. 57-58. GARCiA-SOTO MATEOS, E., "Grabados antropomortos de la cueva de Penches (Barcina de los Montes, Burgos). Algunas precisiones sobre su interpretación y significado", Homenaje al Profesor D. Martín Almagro, Madrid 1983, t. I, págs. 301-316.

${ }^{23}$ Osaba y Ruiz de ERenchun, B., La arqueologia en Ojo Guareña, Revista de Archivos, Bibliotecas y Museos, t. LXVIII, 1 (1960), págs. 177-192; JORDA CERDA, F., "Nuevas representaciones en Ojo Guareña (Burgos)", Zephyrus, XIX-XX (1968-69), págs. 61-71; URIBARRI, J. L., y LIZ, C., "El arte rupestre...", citado; Ortega Martinez, A. I., y Martin Merino, M. A., "La arqueología del Karst...", citado.

${ }^{24}$ Moure Romanillo, J. A., y Garcia-Soto Mateos, E., "Los grabados de la Cueva de San García...", citado, pág. 203.

${ }^{25}$ LlanOS, A., “Excavaciones en la cavidad de Solacueva de Lacozmonte (Jócano, Álava)", Campañas de 1980-1981, en prensa.

${ }^{26}$ Apellaniz, J. M., y Domingo Mena, S., "Estudios sobre Atapuerca...", citado, pág. 25, fig. 5 y 98; Municio GonzÁlez, L., y Piñón VARELA, F., "Programa de documentación...", citado, págs. 139-140 y "Cueva de Los Enebralejos...", citado, pág. 71. 
Frente a esta concreta filiación cronológico-cultural de los grabados en cuevas, se sitúan los grabados al aire libre de incierta cronología y autoría, sin contextos arqueológicos precisos y con muestras evidentes de modernidad en gran parte de sus motivos. Se trataria de un complejo mundo rupestre caracterizado por el empleo de técnicas de repiqueteado, incisiones profundas y abrasiones que, unas veces en rudo esquematismo y otras en tosco naturalismo, describen un amplio abanico de tipos entre los que predominan figuraciones antropomórficas y cruciformes, animalísticas, cazoletas y herraduras y una densa gama de circuliformes, espiraliformes y motivos de variado trazado geometrizante. La distribución de esta manifestación artística por toda la Península Ibérica y su descubrimiento paralelo al de la pintura esquemática, no bastaron para que se les dedicara la atención precisa en la investigación, realizándose su estudio sólo de forma marginal y en relación con la pintura esquemática ${ }^{27}$. Se les ha querido explicar como resultado de una expansión hacia el Este, Sur y Suroeste de los grabados gallegos y portugueses cuando estos tienden a desaparecer en las zonas que les son propias ${ }^{28}$, mas la falta de sistematización de sus focos más característicos, su carácter inhábil ${ }^{29}$ y su más que dudosa filiación prehistórica ha venido determinando un abandono en su investigación y la repetición tópica, cuando esta se ha hecho, de una cronologia abarcable desde el Eneolítico a la Edad Media.

Los grabados al aire libre sorianos se localizan - con la excepción de Cueva Grande, hallazgos sueltos de la cabecera del Duero y Cueva de La Santa Cruz - en covachos y abrigos situados en lugares prominentes y destacados, de amplia visibilidad desde los mismos y formando parte de grandes cuerdas rocosas que recorren, en orientación W-SW,

${ }^{27}$ Las notas bibliográficas sobre este particular, aparte de abundantes, son y están muy dispersas por revistas especializadas, regionales y locales. Se carece de un estudio de conjunto si bien Jordá Cerdá, Ripoll Perelló, Beltrán Martínez, Acosta Martínez, Balbín Behrmann, Mauro Hernández y un largo etc. de investigadores se han ocupado de ellos si quiera marginalmente. Su relación con la pintura esquemática ha sido una constante como puede verse en AcostA, P., La Pintura Rupestre Esquemática en España, Salamanca 1968, págs. 186-187.

${ }^{28}$ Nieto Gallo, G., "La Península Ibérica al final del II y comienzos del I milenio antes de Cristo hasta la aparición del Hierro", en Historia General de España y América: los origenes de España, t. I. 1, Madrid, Ed. Rialp, 1985, págs. 493-499; JORDA CERDA, F., «EI arte de los pueblos agricultores, ganaderos y metalúrgicos", en Historia del Arte Hispánico, I: La Antigüedad, Madrid, Ed. Alhambra, 1978, pág. 148.

${ }^{29}$ BeltRAN MARTinez, A., Los parques culturales y el arte rupestre en Aragón, Zaragoza. Diputación General de Aragón, 1989, pàg. 43. 


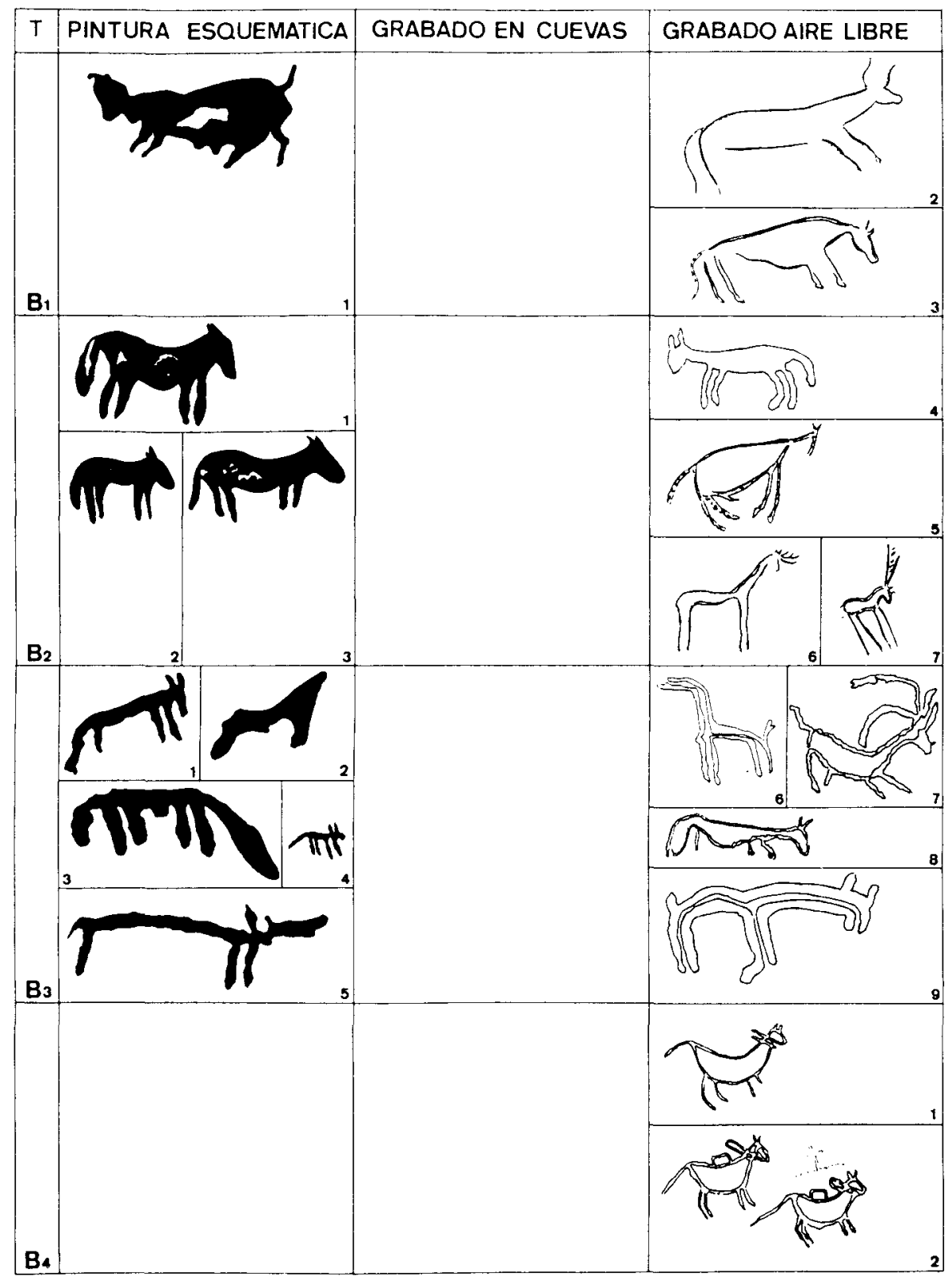

Fig. 6. Tipología comparada: cuadrúpedos.

B.1: 1: Cueva Grande; 2 y 3: Abrigo 9 de Valvenedizo-Castro.-B.2: 1. 2 y 3: La Cuerda del Torilejo; 4: Grupo 2.A de Tiermes-Sotillos; 5: Abrigo 9 de Valvenedizo-Castro: 
amplios espacios limitando barrancos, valles o cañadas en áreas de parameras, zonas arrasadas y marginales, con características de comarca de montaña muy apropiada para el pastoreo. En su mayoría aparecen en estaciones próximas a diferentes cursos de agua y otras se enclavan en lugares de paso entre montañas. $Y$, en general, ofrecen una temática variada, susceptible de ser concentrada en dos grandes grupos según representen figuraciones, más o menos relacionables con un modelo real cognoscible, o composiciones abstractas, lineales o geométricas, que determinarian quince tipos (antropomorfos, cuadrúpedos, jinetes, circuliformes, petroglifoides, ídolos, barras, puntos, cazoletas, zig-zags, serpentiformes, herraduras, tectiformes, esteliformes y restos lineales), una constante repetitiva expresada en la presencia masiva del motivo en herradura, de las cazolestas y de la figura humana y animal - con cierto diseño naturalista y abundancia del jinete- en todos los núcleos y la escasez de motivos ídolos, petroglifoides, espiraliformes y esteliformes.

Del análisis técnico de los distintos motivos que dan forma a estos modelos tipológicos se infiere el uso de un grabado en surco, resultante de la aplicación de técnicas de repiqueteado - en su gran mayoria- e incisiones sobre las que actúan, en menor medida, otras abrasivas. No son pocos los ejemplos en los que se contemplan repasos posteriores que, asi como afirman la pervivencia de cierta inquietud (¿artística?. ¿religiosa?) y utilización tradicional del lugar (Conquezuela), han ocasionado alteraciones y pérdidas del motivo original.

Como se afirmaba anteriormente, no se da en la provincia de Soria ningún yacimiento arqueológico definido que pueda ponerse en relación directa con alguno de los núcleos de grabados al aire libre. Las referencias arqueológicas con las que se han venido asociando los grabados se apoyan, tan sólo, en hallazgos sueltos, mal definidos y peor localizados, dudosamente relacionables con las manifestaciones artísticas aunque, eso sí, señalarian un horizonte cultural para la zona de raíces calcolíticas, amplio desarrollo hasta el Bronce Medio con asentamientos dispersos y alineados a lo largo del piedemonte del Sistema Central, prolongación en la Edad del Hierro romanización y pervivencias hasta la Edad Media. Todo ello estaría en base a un dominio económico ganadero-pastoril que nos inclinan a pensar, tras los análisis descriptivos, tipológicos y técnicos, que los grabados del suroeste soriano fueron obra de una comunidad

$\leftarrow$

6: Abrigo 6 de Valvenedizo-Castro; 7: Grupo 3.H del Barranco de la Mata.-B.3: 1: Peña Somera; 2: Abrigo del Pozo; 3: Cueva Grande; 4: Peñón del Majuelo; 5: Peña Somera; 6: Abrigo 6 del Valle del Rio Manzanares; 7: Grupo 7.A de Tiermes-Sotillos; 8: Abrigo 5.B del Barranco de la Mata; 9: Abrigo 5 de Tiermes-Sotillos.-B.4: 1 y 2: Abrigo 2 del Barranco de la Mata. 

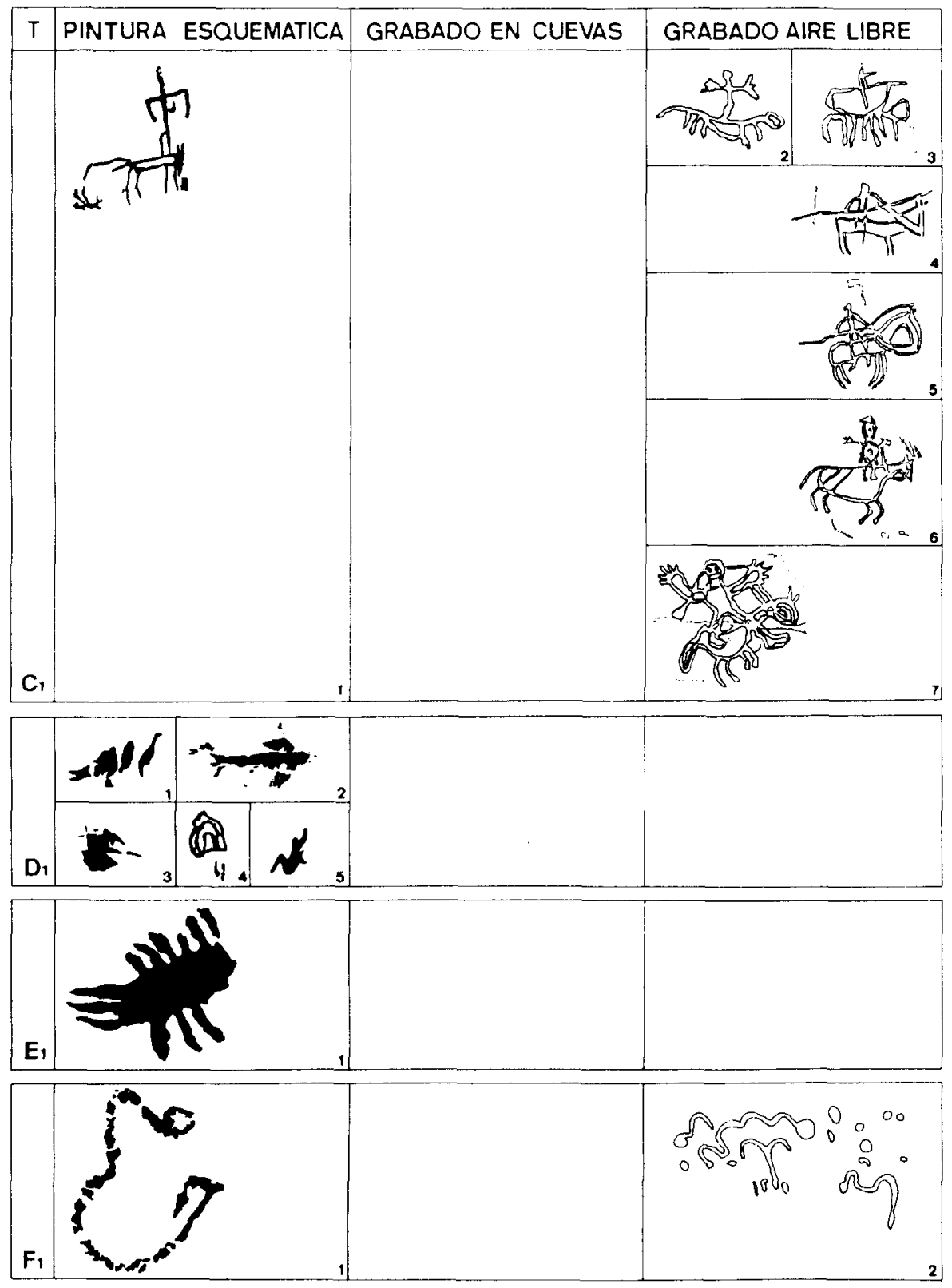

Fig. 7. Tipologia comparada: C: Jinetes; D: Aves; E: Peces y F: Serpentiformes.

C.1: 1: Prado de Santa Maria; 2: Abrigo 3 del Valle del Río Manzanares; 3: Abrigo 10 del Barranco de la Mata; 4: Grupo 3J del Barranco de la Mata; 5: Abrigo 9 del Barranco 
marginal y retardataria (de amplia prolongación en el tiempo) y economía tradicional de tipo pastoril.

Del inventario-resumen de las estaciones grabadas al aire libre hasta ahora conocidas, su carta de distribución y cuadro sinóptico y gráfica de barras de sus características se desprende, dejando al margen el ciclo galaico-portugués, la dispersión de estas manifestaciones por las estribaciones y piedemonte de las grandes unidades del relieve peninsular, en una localización paralela aunque no coincidente con la pintura esquemática. La utilización de abrigos y covachos como soportes de los grabados, el generalizado uso de técnicos de repiqueteado o picado y la repetición tipológica, dentro de la gran variedad regional observada, de motivos antropomórficos, cruciformes, herraduras, cazoletas y abstractos geométricos, son afinidades comunes en el conjunto de los grabados al aire libre de la Península Ibérica, entre los que los sorianos tienen un peso específico propio. Arqueológicamente sólo los grabados de EI Pedroso ${ }^{30}$ y Yecla de Yeltes $^{31}$ aparecen claramente relacionados con yacimientos materiales mientras que el resto de los grupos se les ha venido asociando a un horizonte cultural Calcolitico y Edad del Bronce en general en razón de su proximidad o comparación de alguno de sus motivos con diversos hallazgos semejantes en apreciación cronológica ${ }^{32}$. No se descarta, tampoco, una larga pervivencia que llevaría a muchos de ellos a una datación en la Edad del Hierro, romanización y Edad

30 Esparza Arroyo, A., "El castro zamorano del Pedroso y sus insculturas", BSAA, XLIII (1977), págs. 27-39.

${ }^{31}$ MARTIN VALLS, R., "Insculturas del castro salmantino de Yecla de Yeltes: nuevos hallazgos y problemas cronológicos", BSAA, XXXIX (1973), págs. 81-103; "La necrópolis del castro de Yecla de Yeltes. Datos arqueológicos y epigráficos para su estudio", Zephyrus, XXXIV-XXXV (1982), págs. 181-182 y "Las insculturas del castro salmantino de Yecla y Yeltes y sus relaciones con los petroglifos gallegos", Zephyrus, XXXVI (1983), págs. 217-231.

32 Garcia Sanchez, M. y Spahni, J. C., "Grabados rupestres esquemáticos de época eneolítica, en Baños de Alicún (Granada)", Archivo de Prehistoria Levantina, VII (1958), pág. 121; DEL AMO, M., “Los grabados rupestres de Los Aulagares (Zalamea la Real, Huelva)", Miscelánea Ampuritana. XXV Aniversario de los Cursos de Ampurias (1947-1971), vol. I, 1974, págs. 69-86; ATRIAN JORDAN, P., "Los grabados rupestres del Barranco Cardoso, Almohaja (Teruel)", Rev. Teruel, 64 (1980), págs. 113-125; Benavente Serrano, J. A., "Los grabados rupestres de La Coscollosa (Alcañiz, Teruel)", Bajo Aragón. Prehistoria, VIIVIII (1986-87), págs. 107-118.

$\leftarrow$ de la Mata; 6: La Cañada del Monte y 7: Los Poyatillos.-D.1: 1: Peñón del Camino de Pedrajas; 2: La Cuerda del Torilejo: 3 y 4: El Mirador y 5: Los Peñascales III.-E.1: 1: Abrigo del Pozo.-F. 1: 1: Prado de Santa Maria; 2. La Cueva de La Santa Cruz. 
JUAN A. GOOMEZ-BARRERA
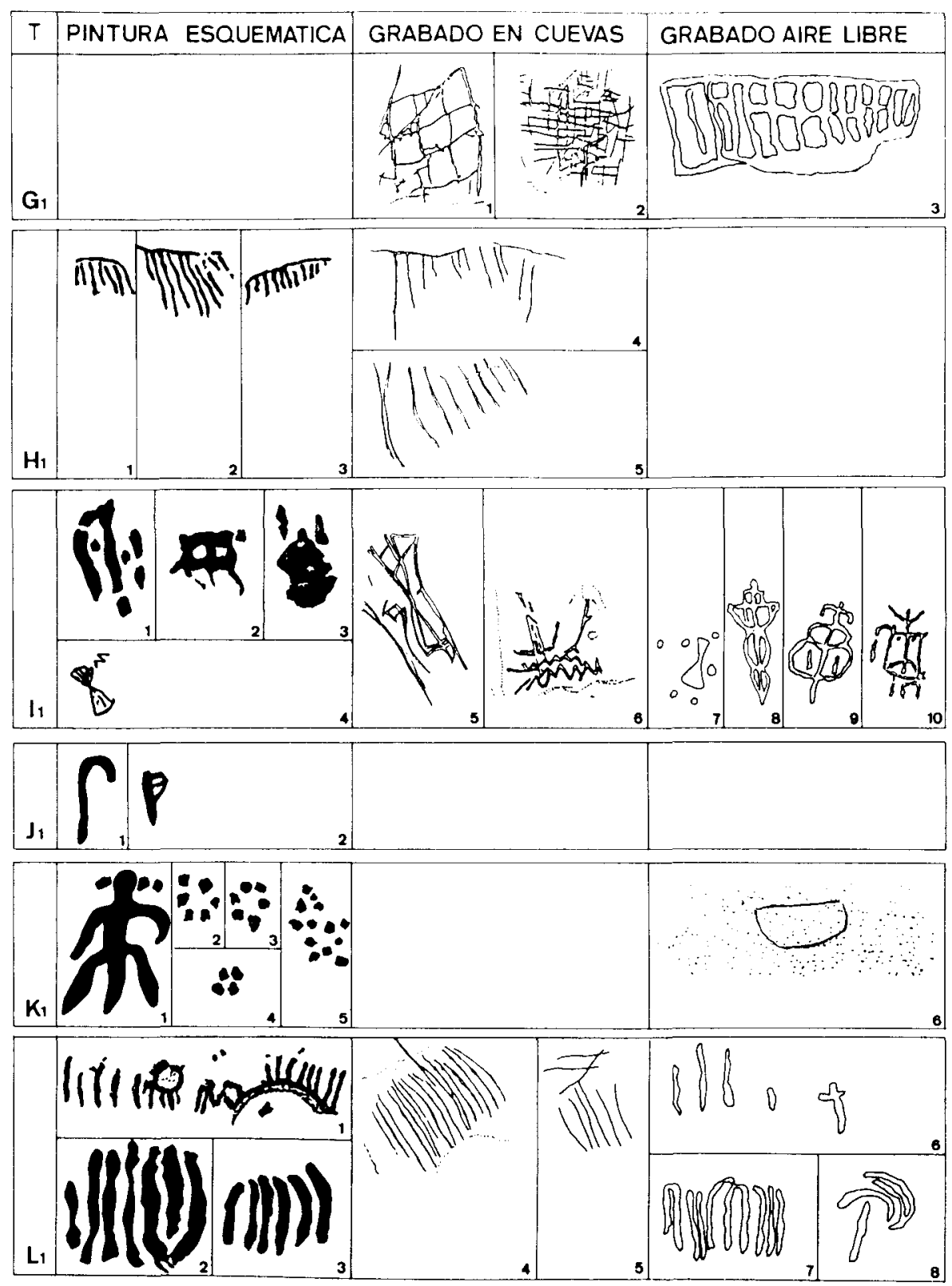

Fig. 8. Tipología comparada: G: Reticulas; H: Pectiniformes; I: Idolos; J: Armas; $K$ : Puntos y L: Barras. 
Media ${ }^{33}$. Si parece claro, por contra, su ambientación en un sistema económico basado en el pastoreo y en una agricultura marginal ${ }^{34}$.

A gran parte de estas muestras plásticas se les ha venido situando en un mundo arqueológico dolménico ante la presencia de insculturas - pinturas - de igual tono en alguno de sus ortostatos, circunstancia ésta utilizada para establecer el momento más antiguo del fenómeno esquemático grabado ${ }^{35}$. Es la misma relación que se ha querido ver con la pintura esquemática, acentuada por la general aparición de las pictografías en abrigos y covachos al aire libre, la coincidencia repetitiva de alguno de sus motivos y un horizonte cultural basado en evidencias arqueológicas tan precarias como las que acompañan a los grabados. Se pueden concretar "grabados asimilables" a la pintura esquemática, derivados o copiados de ésta; otros que paralelizan más con los grabados gallegos y podrian ser consecuencia de la difusión, como señalara Jordá Cerdá, de las manifestaciones "atlánticas" por el interior peninsular; y un tercer grupo, mixto de los anteriores, con pervivencia de viejas ideas y derivaciones locales. Esta clasificación apoyada en los criterios de

33 Álvarez Garcia, A. y Cebolla Berlanga, J. L., "Los grabados nupestres de Las Peñetas, Nonaspe (Zaragoza)", Cuademos de Estudio Caspolinos, XI (1985), págs. 157-166; Diez-CoRoneL, L., "Grabados rupestres prehistóricos en el Pinneo lenidano y andorrano del tipo Roca de Bruixes

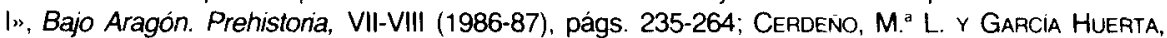
R., "Noticia preliminar de los grabados de la Peña Escrita (Canales de Molina, Guadalajara)", Zephyrus, XXXVI (1983), págs. 179-186, por citar tan sólo tres casos en los que la cronologia de sus grabados puede alcanzar las notas esbozadas.

${ }^{34}$ Esta idea nos parece obvia en la mayoria de las estaciones grabadas en la línea marcada por BLAS CORTINA, M. A., "Los grabados rupestres del Picu Berrubia", Ampurias, 36 (1974), págs. 63-86

${ }^{35}$ Como en el caso de Picu Berrubia, podemos citar los grabados de Peña Tú, Muñogalindo (LOPEZ PLAZA, S., "Grabados rupestres esquemáticos en Muñogalindo (Ávila)", Zephyrus, XXXVI, 1983, pág. 203). Los Aulagares (DEL AMO, M., “Los grabados rupestres...", citado, págs. 69-86), Arquillo de los Porqueros (GIMENEZ REINA, S., "Los grabados rupestres del Arquillo de los Porqueros (Antequera, Málaga)", en Libro Homenaje al Conde de la Vega del Sella, Oviedo 1956, págs. 207-219) En este sentido son de gran interés las aportaciones cronológicas de Delibes DE CAStro, G. Y Rojo Guerra, M., "Pintura esquemática en el sepulcro de corredor burgalés de "El Moreco", Huidobro", Arqueología, 20, Porto GEAP, 1989, págs. 49-55.

G.1: 1 y 2: Cueva Maja; 3: La Cerrada de La Solana.-H.1.: 1, 2 y 3: Umbria del Colladillo; 4: Cueva Maja y 5: Covarrubias. -1.1: 1: La Peñota; 2: Abrigo del Oeste; 3: Abrigo del Este; 4: El Mirador; 5: Covarrubias; 6: Cueva Maja; 7: Cueva de La Santa Cruz; 8: Cueva Grande; 9: Grupo 7.H de Tiermes-Sotillos y 10: Grupo 7.1 de Tiermes-Sotillos-J.1: 1: Covacho del Morro; 2: Covachón del Puntal-K.1: 1: Abrigo 1 del Barranco de Valdecaballos; 2, 3, 4 y 5: El Tolmo de Morellán; 6: Grupo 3.J del Barranco de la Mata.-L.1: 1: Abrigo del Tubo; 2: Abrigo del Pozo; 3: La Peñota; 4: Cueva Maja; 5: Covarrubias; 6 y 8: Grupo 7.H de Tiermes-Sotillos; y 7: Grupo 1.B del Barranco de la Mata. 

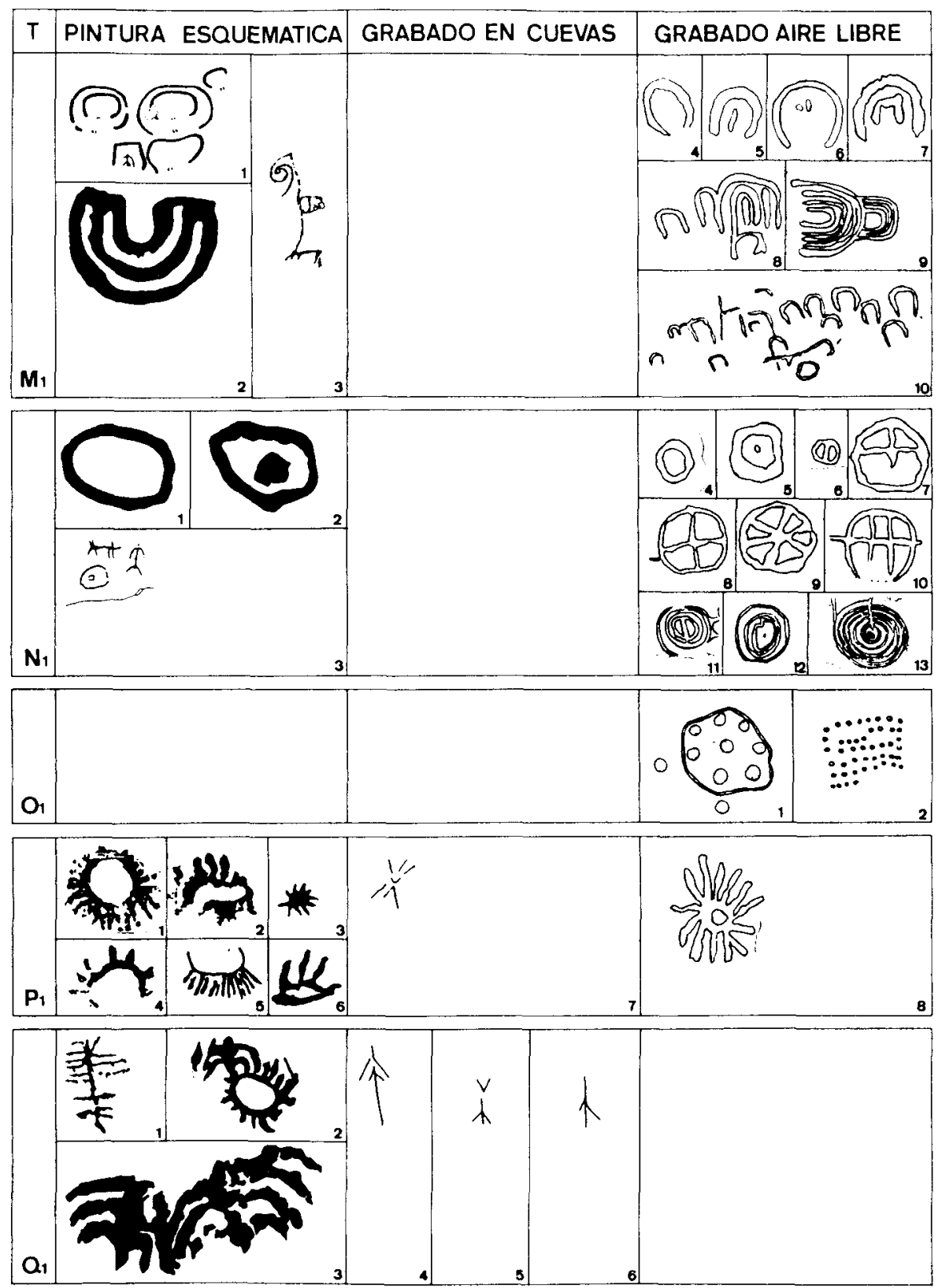

Fig. 9. Tipologia comparada: M: Petroglifoides-Herraduras; N: Circuliformes espiraliformes; O: Cazoletas; P: Esteliformes; Q: Ramiformes. 
Acosta ${ }^{36}$ puede aplicarse, con mayor o menor intensidad según las zonas, al conjunto de los grabados al aire libre de la Península Ibérica y concretar así el origen de los mismos que, dada la escasa asociación en un mismo motivo o panel de pintura y grabado y la distribución próxima pero no coincidente de sus estaciones, hizo pensar a Fortea estaria en los momentos finales de la pintura considerando al grabado un «eco" tardío de ésta ${ }^{37}$.

En el Alto Valle del Duero se ha podido concretar lo aqui expuesto. La diferenciación entre la pintura esquemática y el grabado no sólo se manifiesta en las diversas técnicas usadas en sus trazados y en la distinta distribución zonal de sus yacimientos si no, también, en una serie de particularidades relacionadas con la temática y su reiteración, aspectos, por lo demás, tenidos siempre como definitivos en sus asociaciones. Los tres ciclos artísticos reconocidos en territorio soriano han sido sometidos a un análisis tipológico comparado a través del cual han quedado en evidencia los escasos contactos existentes entre grabados al aire libre y grabados en cuevas, se ha determinado una coincidencia notable entre estos últimos y la pintura esquemática - si bien limitada a la reducida variedad temática de las cavidades- $y$, finalmente, se ha confirmado una más amplia y aparente semejanza entre la pintura y los grabados al aire libre que repiten, en múltiples variantes, los tipos pictóricos esquemáticos a la vez que se desligan de su tradición con la presencia de motivos extremos (figuras humanas realistas, cruciformes, jinetes y elementos geometrizantes) de larga pervivencia.

Con todo, y como mera hipótesis de trabajo deducible de las investigaciones artístico-arqueológicas aqui esbozadas, proponemos como cronología base del estudio del arte rupestre postpaleolítico del Alto Duero,

${ }^{36}$ Acosta, P., "Arte rupestre postpaleolítico hispano", en Historia de España. 1. Prehistoria, Madrid, Ed. Gredos, 1986, págs. 290-291.

${ }^{37}$ FORTEA, J., "Grabados rupestres esquemáticos en la provincia de Jaén", Zephyrus, XXI-XXII (1970-71), págs. 139-156.

\section{$\leftarrow$}

M.1: 1: La Asomadilla; 2: Umbria del Colladillo; 3: La Cuerda del Torilejo; 4-7: Cañada del Monte; 8: Abrigo 11 del Barranco de la Mata; 9: Grupo 1.B del Barranco de la Mata y 10: Abrigo 9 del Barranco de la Mata.

N.1: 1 y 2: Covacho del Morro: 3: La Peña los Plantios; 4 y 5: Abrigo 3 de La Cañada del Monte; 6: Abrigo 11.B del Barranco de la Mata; 7: La Cerrada de la Solana; 8: Cueva de La Santa Cruz; 9: La Cerrada de la Solana; 10: Abrigo 13 del Valle del Río Manzanares; 11 y 13: Abrigo 3.D del Barranco de la Mata y 12: Abrigo 6.A del Barranco de la Mata.

$0.1: 1:$ Abrigo núm. 2 de Valvenedizo-Castro; 2: Abrigo núm. 5 de Valvenedizo-Castro.

P.1: 1: El Mirador; 2: Abrigo del Pozo; 3: Peñón del Majuelo; 4: La Tronera; 5: El Mirador; 6: Abrigo del Pozo; 7: Cueva Mayor y 8: La Cerrada de la Solana.

Q.1: 1: El Prado de Santa Maria; 2 y 3: El Mirador; 4, 5 y 6: Cueva Mayor. 

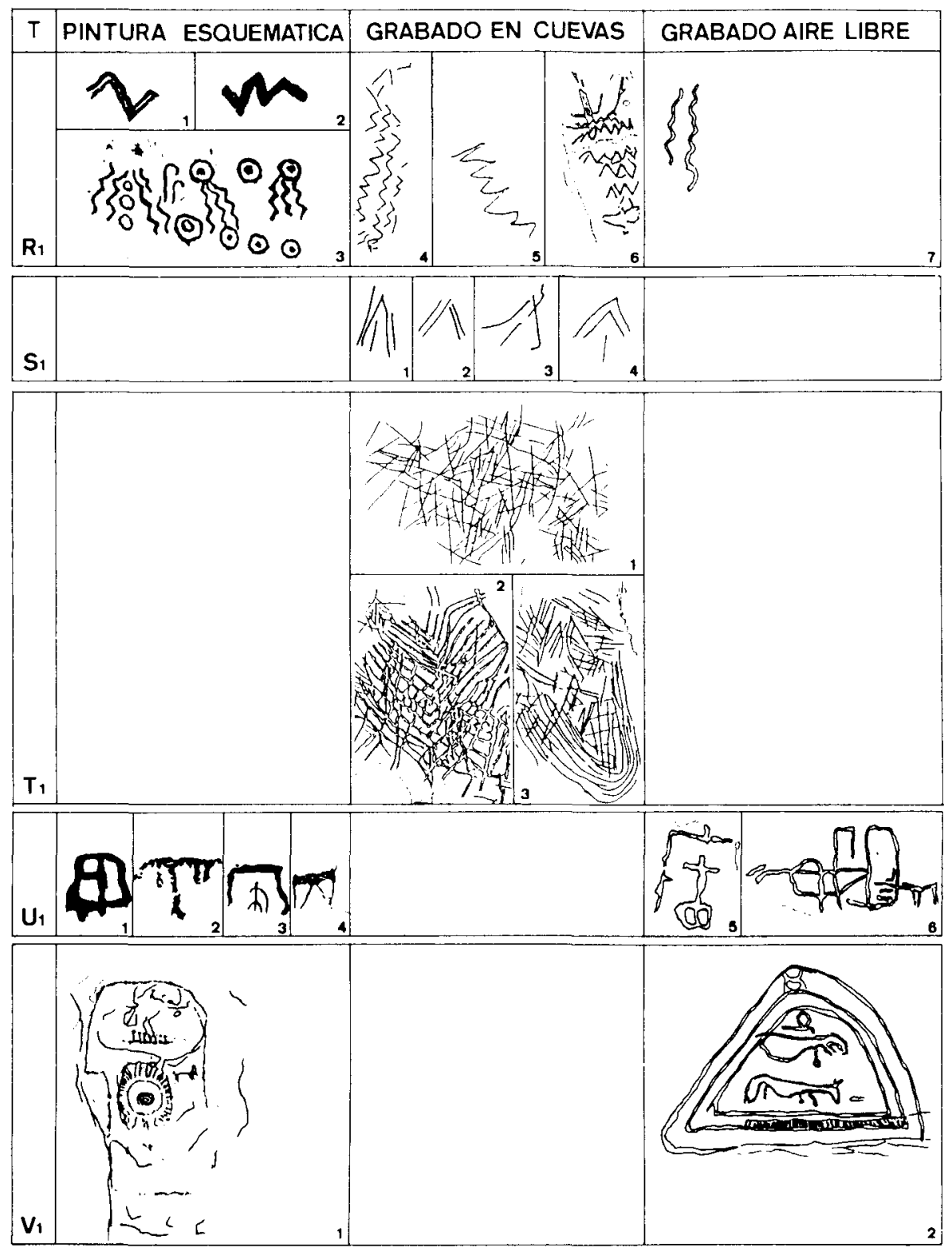

Fig. 10. Tipología comparada: R: Zig-zags; S: Anguliformes; T: Marañas; U: Estructuras; y V: Estelas. 
un secuencia evolutiva que arrancaría en el Calcolítico con el inicio de las formas esquemáticas pintadas y grabadas en cuevas; se prolongaría con un amplio desarrolio de éstas a lo largo del Bronce Antiguo para, a partir del Bronce Medio, y como consecuencia del descenso poblacional denunciado por la escasez de yacimientos correspondientes a este periodo, producirse un debilitamiento artístico que, sin embargo, no impediría la pervivencia de la tradición esquemática a lo largo del Bronce Final y Primera Edad del Hierro con la incorporación, incluso, de motivos nuevos ("trisceles" del Covachón del Puntal y motivo-estela de La Peña los Plantíos) ${ }^{38}$. El recuerdo de la vieja práctica pictórica conllevaria, en poblaciones marginales de economía pastoril, la aparición, ya desde el Bronce Medio, del grabado al aire libre que, en diseños más toscos y rudos en consonancia con las posibilidades técnicas de sus autores, veremos prolongarse por la Edad del Hierro, romanización y Edad Media con reducidos, aunque significativos, cambios en su temática.

¿Se puede concluir, en el estado actual de investigación, algo concreto sobre interpretación y significado del arte rupestre esquemático? ¿Sirven las viejas ideas religiosas y funerarias como explicación última del esquematismo? ¿Acaso el determinismo geográfico y tipológico de Acosta ${ }^{39}$ es suficiente para desecharlas y avalar la teoría ideográfica? ¿Tenemos la información suficiente para adentrarnos en estudios interpretativos? Con la clara intención de búsqueda de respuestas se ha identificado a los abrigos y a las cuevas con manifestaciones artísticas como "santuarios", se ha determinado el carácter cultural de elementos individualizados como ramiformes, petroglifoides, tectiformes, soliformes, etc., y se ha sancionado la trascendentalidad sacral de aquellas actividades, aspectos o acontecimientos de la vida que tenían algún sentido para el

38 Jimeno martínez, A, y Fernández Moreno, J. J., "El poblamiento desde el Neolítico a la Edad del Bronce: constantes y cambios", II Symposium de Arqueologia Soriana (en prensa); Jimeno Martinez, A. y Gomez-Baraera, J. A., "En tomo al "trisceles" del "Covachón del Puntal" (Valonsadero, Soria) y la cronología de la pintura esquemática del Alto Duero", Zephyrus, XXXVI (1983), págs. 195-202; y GómEZ-BARRERA, J. A., "El motivo-estela de "La Peña los Plantios" (Fuentetoba, Soria)», Soria Arqueológica, 1, en prensa.

39 Acosta, P., "La pintura rupestre...", citado.

R.1: 1 y 2: El Mirador; 3: Covacho del Morro; 4: Grupo F de Cueva Maja; 5: Grupo I de Cueva Maja; 6: Grupo $A$ de Cueva Maja. - S.1: 1-4: Cueva Mayor de San Bartolomé.-T.1. 1: Covarrubias; 2 y 3: Grupo $O$ de Cueva Maja.-U.1: 1: Murallón del Puntal; 2: La Cuerda del Torilejo; 3: La Asomadilla; 4: El Mirador; 5: Abrigo 2 del Valle del Rio Manzanares; 6: Abrigo 7 del Barranco de la Mata.-V.1: 1: Grupo III de La Peña los Plantios y 2: Abrigo núm. 5 del Barranco de la Mata. 
hombre y la comunidad "esquemática" ${ }^{40}$. $Y$ en esta línea de investigación hemos calificado de santuario al conjunto de Valonsadero y Cueva Maja, admitido la interpretación cultural de diversos motivos y otorgado la idea de trascendentalidad a escenas, asociaciones recurrentes o a figuraciones que definen actividades concretas de los "autores esquemáticos". Mas no creemos con ello haber dado respuesta adecuada a ninguna de las cuestiones formuladas. Sin embargo, tras este amplio estudio y el contacto directo con sus motivos bien podemos concluir que los grabados rupestres postpaleolíticos del Alto Duero se nos presentan como un «producto original elaborado por el hombre artificialmente con la intención de comunicar algo" ${ }^{41}$ y que por ello se han de considerar como una manifestación artística de primer orden, necesaria de este trabajo y de cuantos éste a su vez sea capaz de sugerir.

${ }^{40}$ Grande del Brio, R., La pintura rupestre esquemática en el centro-oeste de Espana (Salamanca y Zamora), Salamanca, Excma. Diputación, 1987, págs. 189-196.

${ }^{41}$ Fernandez Arenas, J., Teoria y metodologia de la Historia del Arte, Barcelona Anthropos, (2. ${ }^{a}$ ed., 1984), pág. 27. 